\section{The relationship of self-reported affect to performance in serial learning}

\author{
MARTIN KATAHN, C. R. SNYDER, and \\ JOSEPH A, DURLAK, Vanderbilt \\ University, Nashville, Tenn. 37203
}

Affect self-report ratings were taken before, during, and after Montague's (1953) easy (noncompetitive) and hard (competitive) serial lists. Increased excitement, anxiety, unpleasantness, tenseness, and annoyance were related significantly to poorer performance on the hard list but not on the easy list. Compared with resting levels, significantly more negative affect was experienced during performance on the hard than on the easy list. The experience of negative affect preceded the main decrement in performance.

There has been much research relating anxiety (only one of the many affects) and performance, and considerable research using affect change as a dependent variable, but little attention has been given to the relation of a broader range of affects at the time of a task with performance on that task. Methodology for the current experiment was conceived in the light of several lines of research.

One of the most popular ways of studying the relationship of self-reported affect to performance involves the use of a scale, such as the Taylor Manifest Anxiety Scale, given weeks in advance of the experiment (Lucas, 1952; Montague, 1953). The experimental situation not only occurs at an extended time period after obtaining the anxiety measurement, but in a different environmental setting as well, and the $E$ assumes that the level of anxiety being experienced is directly related to the anxiety level indicated by the questionnaire. These factors are probably related to the failure to obtain consistent relationships between general anxiety and various learning situations, although more consistent results have been obtained when a situationally specific anxiety scale such as the Test Anxiety Questionnaire is employed (Sarason, 1960). O'Neil et al (1969) have noted that the measurement of anxiety during the actual experimental task is the most meaningful alternative in this research area. Following this line of reasoning, the first purpose of the current experiment was to correlate anxiety self-report ratings, taken during a serial-learning task, with performance on that task.
The effects of various manipulations upon affects other than anxiety as the dependent variable have been researched, but affect at the time of a task has not been correlated with performance on that task. Typically, studies have used some sort of adjective checklist as the dependent variable. Either the Mood Adjective Check List (Nowlis, 1964) or the Multiple Affect Adjective Check List (Zuckerman, 1960) has been employed to ascertain affect changes. Unlike the previous body of research employing pretest and posttest affect change as the dependent variable, the current study sought to relate various affects experienced during a task with performance on that task. Thus, the second purpose of the experiment was to ascertain the relationship of performance to affect self-reports taken before, during, and after a serial list. In addition to Wundt's (1907) original scales of calm-excited, pleasant-unpleasant, and relaxed-tense, the scales nonanxious-anxious, boredinterested, and satisfied-annoyed were added.

\section{SUBJECTS}

Forty students (30 males and 10 females) were chosen randomly to participate in the experiment as part of their requirements for an introductory psychology course at Vanderbilt University.

\section{APPARATUS AND STIMULUS LISTS}

Practice lists of 6 nonsense syllables each and test lists of 12 nonsense syllables each were typed on a continuous roll of white paper. One practice list and one test list employed syllables rated at .25 in association on the Glaze scale, while one practice and one test list employed syllables rated at .90 in association value (Glaze, 1928). These were the same lists used by Montague (1953) and are considered to contain much intralist competition among items in the former case and little intralist competition in the latter. The second list is easier to learn than the first. Each syllable was presented serially on a Lafayette memory drum for a $2-\mathrm{sec}$ exposure, with $2 \mathrm{sec}$ between exposures and an intertrial interval of $6 \mathrm{sec}$.

\section{DESIGN}

The design was a 2 by 2 by 2 factorial, with practice list, test list, and $\mathrm{E}$ as variables. The Ss either learned a hard ( .25 in association value) or easy (.90 in association value) practice list and were then switched to a hard (.25 in association value) or easy (.90 in association value) test list. The initial practice lists were employed to allow the $S$ to familiarize himself with the experiment and to ascertain whether a hard or easy practice list had a differential effect on performance on a subsequent hard or easy test list. Two male Es were used to strengthen replicatory power.

$$
\text { PROCEDURE }
$$

The $S$ was seated before the memory drum and given standard serial-anticipation instructions, after which he filled out a self-report scale for the first time. The self-report scale consisted of the affect polar opposites cited in the introduction, with each pair of words separated by numbers, 1 through 10 . Number 1 denoted the first of the pair of words, and No. 10 denoted the second. The $S$ indicated the applicability of each pair of words by circling any number from 1 to 10 . Next, the $S$ took the practice list for four trials, filled out the self-report scale for the second time, and began on the test list. After two runs through the test list, the S was stopped to complete the self-report scale for the third time and then recommenced on the test list until he achieved one perfect trial or a maximum of 40 trials. The $S$ completed the experiment by taking the self-report scale for the fourth time.

\section{RESULTS}

Using trials to criterion on the test list, scores were entered in a three-way analysis of variance, with the between variables practice list (easy or hard), test list (easy or hard), and $E(N=2)$. Figure 1 shows a

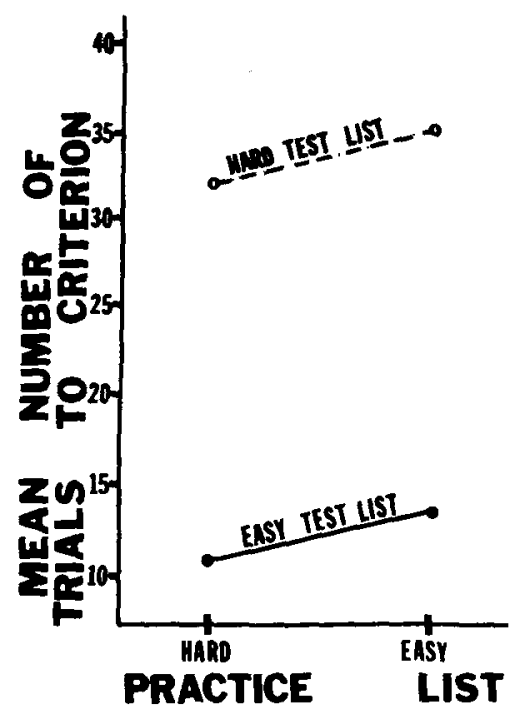

Fig. 1. Mean number of trials to criterion for the hard and easy test lists as a function of hard or easy practice lists. 
trend for the harder of the two conditions of practice list to be associated with better performance $(F=2.18, \quad \mathrm{~d} f=1 / 32$, $\mathrm{p}<.145)$. A strong main effect of test list was obtained $(F=102.88, \quad \mathrm{df}=1 / 32$. $\mathrm{p}<.001)$. No effect of $\mathrm{E}$ was obtained $(F=.02, \quad d f=1 / 32, \quad p<.878) . \quad$ All interactions were nonsignificant.

Because the effects of differences in practice list on test-list performance were not significant, the data were treated only in terms of hard or easy test list in further analyses. The correlation of each affect scale, at all four points in the experiment, with trials to criterion on either the hard or easy test list is shown in Table 1. Although not significant at the four points in the experiment, the correlations for the easy list were predominantly positive, such that the more excited, anxious, unpleasant, tense, and annoyed the $S$ reported he felt, the more trials he took to reach criterion.

For the hard test list, the correlations of affect self-report ratings made before and after performance were not generally significant (see Table 1). However, for ratings made during the hard list, greater excitement, anxiety, unpleasantness, tenseness, and annoyance experienced at Trial 2 were associated with a significantly greater number of trials to criterion.

In order to ascertain if there was a change in affect due to the taking of the test lists, the six mean affect self-report ratings were analyzed in a two-way analysis of variance, with the variables of time (before or during the test list) and list (easy or hard test list). Affective experience tended to be more negative during the test lists $(\mathrm{F}=3.16, \mathrm{df}=1 / 20, \mathrm{p}<.10)$. A significant interaction of time and list $(F=5.04, \quad \mathrm{df}=1 / 20, \quad \mathrm{p}<.04)$ indicated that affect increased from before to during the hard test list, while affects remained fairly constant for the easy test list. In further post hoc comparisons via t tests, none of the six affects significantly increased from before to during the easy test list. However, for comparisons of affects before and during the hard test list, $t$ tests. showed that four of the affects increased at the .01 level, and the two other affects increased at the .15 level. Thus, affect increased from before to during the hard test list only.

Table 1

The Correlation of Affect Scales with Trials to Criterion on the Easy or Hard Test List at Four Points in the Experiment

\begin{tabular}{|c|c|c|c|c|c|c|c|c|}
\hline & \multicolumn{2}{|c|}{$\begin{array}{c}\text { Before } \\
\text { Practice List }\end{array}$} & \multicolumn{2}{|c|}{$\begin{array}{c}\text { After } \\
\text { Practice List }\end{array}$} & \multicolumn{2}{|c|}{$\begin{array}{c}\text { During } \\
\text { Test List }\end{array}$} & \multicolumn{2}{|c|}{$\begin{array}{c}\text { After } \\
\text { Test List }\end{array}$} \\
\hline & Easy & Hard & Easy & Hard & Easy & Hard & Easy & Hard \\
\hline Calm-Excited & -.106 & .025 & .352 & .294 & .370 & $.608 * * *$ & .357 & -.003 \\
\hline Nonanxious-Anxious & .023 & .068 & .377 & .157 & .280 & $.474^{*}$ & .037 & -.133 \\
\hline Pleasant-Unpleasant & .227 & .127 & .366 & .306 & .347 & $.718 * * * *$ & .172 & .350 \\
\hline Relaxed-Tense & .273 & .021 & $.472^{*}$ & .404 & .359 & $.572 * * *$ & .395 & .187 \\
\hline Bored-Interested & -.227 & -.241 & .065 & -.065 & .047 & -.132 & -.133 & -.342 \\
\hline Satisfied-Annoyed & .004 & .285 & .345 & $.568^{* * * *}$ & .313 & $.703^{* * * *}$ & .366 & $.466^{*}$ \\
\hline
\end{tabular}

\section{DISCUSSION}

Performance on the hard list was associated with a significant increase in negative affective experience, while performance on the easy list was not. During the hard list, poorer performance was related to more negative affective experience.

An important question to ask is whether an $\mathbf{S}$ was feeling strong affects and thereby performing more poorly or performing poorly and feeling strong affects because of his performance. The former explanation seems most plausible for the current experiment. Self-reported affect on Trial 2 of the test list correlated negatively and nonsignificantly (an average correlation of -.28 ) with the number of syllables correct on that trial. For the hard test list, then, affects did not correlate significantly with performance on an early trial, but over all six trials affect did significantly relate to poorer performance. Thus, the experience of strong affect evidently preceded the main performance decrement. Irrespective of the causality of affect, the current experiment supports the common-sense notion that strong affect is associated with poor performance on a task of a complex nature.

The current study offered an opportunity to have $\mathrm{Ss}$ give self-report ratings while actually participating in the experiment. Although these ratings are not necessarily more valid than other affect scales, they do offer a more temporally concise look at affect and performance. Interestingly, results showed anxiety to be less well correlated with the task than were the calm-excited, relaxed-tense, pleasant-unpleasant, and satisfied-annoyed scales. The anxiety scale was related to from $1 \%$ to $20 \%$ of the variance depending upon the time of self-report; the other scales accounted for from $1 \%$ to $52 \%$ of the variance. Future research might profitably attempt to relate a broader range of affects at the time of a task to performance on that task and to investigate the directionality of the relationship of affect and performance in other complex verbal-learning tasks.

\section{REFERENCES}

GLAZE, J. A. The associatiw value of nonsense syllables. Journal of General Psychology, 1928, 35, 255-267.

LUCAS, D. D. The interactive effects of anxiety, failure, and intraserial duplication. American Journal of Psychology, 1952, 65, 59-66.

MONTAGUE, E. K. The role of anxiety in serial rote learning. Journal of Experimental Psychology, 1953, 45, 91-96.

NOWLIS, E. K. Research with the Mood Adjective Checklist. In S. S. Tomkins and C. E. Izard (Eds.), Affect. cognition, and personality. New York: Springer, 1964. Pp. 352-387.

O'NEIL. R. F., SPIELBIRGIR. C. D., \& HANSEN, D. F. The effects of state-anxicty and task difficulty on computcr-assisted learning. Journal of Educational Psychology. 1969 , in press.

SARASON, I. G. Empirical tindings and theoretical problems in in: use of anxicty scales. Psychological Bulletin, 1960, 57, 403-415.

WUNDT, W. Outlines of psychology. Translated by Judd, 3rd. rev. English ed. from the 7th. rev. German ed., 1907.

ZUCKERMAN, M. The developinent of an Affect Adjective Check List for the measurement of anxiety. Journal of Consulting Psychology, $1960,24,457-462$. 